\title{
O IMPACTO DA PANDEMIA EM CIRURGIAS GINECOLÓGICAS NO BRASIL DE 2019 A 2021
}

II Congresso Online de Ginecologia e Obstetrícia da Sogise, 2a edição, de 01/11/2021 a 03/11/2021 ISBN dos Anais: 978-65-89908-14-2

MATIAS-; Camila de Melo Cesarino ${ }^{1}$, ARAÚjO; Carolina Gonçalves ${ }^{2}$, PORTO; Fernanda Helena Sales de Paula ${ }^{3}$, ALBUQUERQUE; Luiza Gaigher ${ }^{4}$

\section{RESUMO}

O impacto da pandemia em cirurgias ginecológicas no Brasil de 2019 a 2021. Em dezembro de 2019, surgiu um novo vírus, na China: o Coronavírus 2019 (Sars-COV-2. Este vírus, que se disseminou pelo mundo tem causado um aumento significativo de internações hospitalares com morbidade e mortalidade variáveis. Desta forma, medidas restritivas têm sido adotadas para evitar a disseminação da doença e evitar a sobrecarga dos sistemas de saúde, dentre elas o cancelamento de cirurgias eletivas de todas as especialidades, incluindo a ginecologia e obstetrícia. Este trabalho objetiva mapear o impacto da pandemia na reduçõo de procedimentos ginecológicos nas 5 regiões do Brasil no período de outubro de 2019 a outubro de 2021, assim facilitando o fornecimento de dados nesta área, Série temporal discursiva, sobre o número de procedimentos ginecológicos realizados entre outubro de 2019 a outubro deP 2021, no Brasil. Em agosto de 2020 o total de procedimentos ginecológicos era de 23.164, caindo para 11.860 e chegando a 9.449 em 2021 , evidenciando uma redução de $40,6 \%$ no total de procedimentos realizados no mesmo período. Os efeitos da Pandemia foram sentidos a partir do mês de março de 2020, meses em que havia superlotação de hospitais e medidas de restrição. Isto se mostrou mais evidente nas regiões Sudeste, Sul, e Centro Oeste, com índices de queda de procedimentos em torno de $40 \%$, isto provavelmente se deve ao fato de estas regiões possuírem maior número de atendimentos e maior ocupação de leitos pela pandemia. A importância dos dados encontrados neste artigo deve-se ao fato de que quando consideramos as consequências da diminuição de volume de procedimentos cirúrgicos na área de ginecologia, principalmente para aquelas pacientes que dependem de tratamento cirúrgico precoce para que suas doenças não tenham pior prognóstico, influenciando dramaticamente seu tratatamento e consequentemente sua qualidade de vida. Apesar da apreensão sobre a disseminação pelo SARS COV-2 ter seu respaldo justificado pela sua importância no contexto atual deve-se manter essas pacientes sem tratamento adequado, seria a opção que Ihes traria maior benefício à saúde.

PALAVRAS-CHAVE: Pandemia, Cirurgias, Ginecologia, Indicadores, Epidemiologia 